\title{
Probing alkenoxy radical electronic structure using anion PEI spectroscopy
}

Cite as: J. Chem. Phys. 150, 034302 (2019); https://doi.org/10.1063/1.5064795

Submitted: 08 October 2018 . Accepted: 30 December 2018 . Published Online: 16 January 2019

Kellyn M. Patros, Jennifer E. Mann, Marissa A. Dobulis, Michael C. Thompson, and Caroline Chick Jarrold (D)

\section{ARTICLES YOU MAY BE INTERESTED IN}

\section{A classical ride through a conical intersection}

The Journal of Chemical Physics 150, 034301 (2019); https://doi.org/10.1063/1.5080399

The pure rotational spectrum of the $\mathrm{ZnBr}$ radical $\left(\mathrm{X}^{2} \Sigma^{+}\right)$: Trends in the zinc halide series The Journal of Chemical Physics 150, 034303 (2019); https://doi.org/10.1063/1.5079396

Photoelectron spectroscopy of anthracene and fluoranthene radical anions

The Journal of Chemical Physics 148, 234306 (2018); https://doi.org/10.1063/1.5036757

\section{Lock-in Amplifiers up to $600 \mathrm{MHz}$}
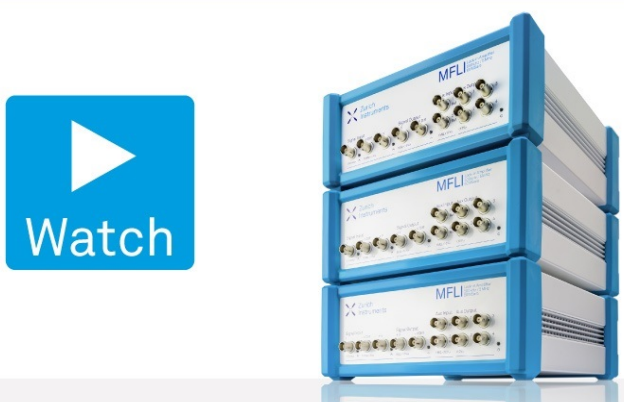

J. Chem. Phys. 150, 034302 (2019); https://doi.org/10.1063/1.5064795 


\title{
Probing alkenoxy radical electronic structure using anion PEI spectroscopy
}

\author{
Cite as: J. Chem. Phys. 150, 034302 (2019); doi: 10.1063/1.5064795 \\ Submitted: 8 October 2018 - Accepted: 30 December 2018 • \\ Published Online: 16 January 2019
}

Kellyn M. Patros, Jennifer E. Mann, ${ }^{\text {a) }}$ Marissa A. Dobulis, Michael C. Thompson, and Caroline Chick Jarrold ${ }^{\text {b }}$

\section{AFFILIATIONS}

Department of Chemistry, Indiana University, 800 East Kirkwood Avenue, Bloomington, Indiana 47405, USA

a) Current address: Physical Electronics, 18725 Lake Drive East, Chanhassen, Minnesota 55317, USA.

b) Author to whom correspondence should be addressed: cjarrold@indiana.edu. Telephone: (812) 856-1190. Fax: (812)855-8300.

\begin{abstract}
Photoelectron imaging spectra of three alkenoxide radical anions (3-buten-1-oxide, 3-buten-2-oxide, and 2-propenoxide) are presented and analyzed with supporting results of density functional theory calculations. In all spectra, intense detachment features are observed at approximately $2 \mathrm{eV}$ electron binding energy, which is similar to the electron affinities of saturated neutral alkoxy radicals [Ramond et al., J. Chem. Phys. 112, 1158 (2000)]. Photoelectron angular distributions suggest the presence of several overlapping transitions which are assigned to the $\tilde{X}$ and $\tilde{A}$ states of multiple energetically competitive conformers. The term energy of the $\tilde{A}$ state of the 2-propenoxy radical, $0.17 \mathrm{eV}$, is higher than that of 3-buten-2-oxy (0.13 eV) and 3-buten-1-oxy $(0.05 \mathrm{eV})$ radicals. Comparing the butenoxy radicals, we infer that stronger interactions between the non-bonding $\mathrm{O} 2 p$ orbitals and the $\pi$ bond increase the splitting between the ground and the first excited state in the 3-buten-2-oxy radical relative to the 3-buten-1-oxy radical.
\end{abstract}

Published under license by AIP Publishing. https://doi.org/10.1063/1.5064795

\section{INTRODUCTION}

Oxidized volatile organic compounds (OVOCs) are present in the atmosphere due to oxidation of hydrocarbon $\operatorname{VOCs}^{1,2}$ as well as direct emission ${ }^{3,4}$ and incomplete combustion of hydrocarbon fuels. ${ }^{5,6}$ OVOCs are key intermediates in the formation of tropospheric ozone which is a greenhouse gas and health hazard. ${ }^{7-9}$ In addition, it has been shown that OVOCs have lower vapor pressures than the corresponding alkanes, ${ }^{10}$ making both wet and dry deposition significant atmospheric sinks. ${ }^{5}$ Deposition of OVOCs is linked to the formation of secondary organic aerosols, which presents health and climate concerns. ${ }^{17,12,9}$

Atmospheric oxidation of VOCs generates alkyl radicals which then react almost exclusively with molecular oxygen. The resulting peroxy radicals can be further oxidized to form alkoxy radicals whose fate is typically $\mathrm{C}-\mathrm{C}$ scission, ${ }^{13-19}$ intramolecular isomerization, ${ }^{13,15,20}$ or $\mathrm{NO} x$ addition. ${ }^{2,21}$ In addition to kinetic studies, ${ }^{22,23}$ the thermodynamic, electronic, vibrational, and rotational structures of several peroxy and alkoxy radicals have been previously explored. ${ }^{24-32}$
Alkoxy radicals, in particular, have close lying X and $\tilde{A}$ states associated with the unpaired electron, nominally being in either of the two non-bonding $2 p$ orbitals on the O-atom. In methoxy radicals, the simplest example, these orbitals are degenerate, resulting in a $\tilde{X}^{2} \mathrm{E}$ ground state that has been the topic of numerous studies. ${ }^{33-54}$ In the lower symmetry ethoxy radical, the degeneracy of the non-bonding $\mathrm{O} 2 p$ orbitals is broken, and the splitting between the $\tilde{\mathrm{X}}$ and the $\tilde{\mathrm{A}}$ states is $364 \mathrm{~cm}^{-1} .^{55}$ Larger alkoxy radicals have conformer-dependent $\tilde{\mathrm{A}}-\tilde{\mathrm{X}}$ splittings, ranging from $50 \mathrm{~cm}^{-1}$ to $1200 \mathrm{~cm}^{-1}$, with typical values of several hundred $\mathrm{cm}^{-1} .{ }^{55}$ The $\tilde{\mathrm{A}}$ states are therefore thermally populated and impact the reactivity of the radicals. The energies of these states have been probed by dispersed fluorescence spectroscopy from higher-lying excited states $^{25,26,29,34,44,50,55}$ or by photoelectron (PE) spectroscopy of the closed shell anionic precursors, $36,57,59,62,63$ the latter of which is lower resolution but offers the advantage of mass selectivity.

In contrast to the simple alkoxy radicals, alkenoxy radicals can have more complex electronic structures. For example, the vinoxy radical $\left(\mathrm{CH}_{2} \mathrm{CHO}\right)$ has vinoxy and formyl-methyl 
resonance forms resulting in delocalization of the radical, and the $\tilde{A}-\tilde{X}$ splitting is approximately $1 \mathrm{eV},{ }^{56-63}$ with the singly occupied molecular orbital being more localized on the beta carbon rather than the O-atom. ${ }^{64}$ Larger $\tilde{\mathrm{A}}-\tilde{\mathrm{X}}$ splittings have been measured from photodetachment spectra of more complex enolates. ${ }^{65,66}$ For allylic oxy radicals, or species with larger separation between the $\mathrm{O}$-atom and the $\pi$ bond, the radical center is localized on the $\mathrm{O}$-atom, but proximity to the $\pi$ bond may impact the $\tilde{\mathrm{A}}-\tilde{\mathrm{X}}$ splitting. In this report, we present the anion PE spectra of 2-propenoxide, 3-buten-2oxide, and 3-buten-1-oxide anions measured using photoelectron imaging (PEI). The results, interpreted with supporting computational studies, suggest that closer proximity of the $\mathrm{O}-$ atom and the $\pi$ bond affects the $\tilde{A}-\tilde{X}$ splitting, which is also conformer-dependent.

\section{METHODS}

\section{A. Experimental}

The anion PEI apparatus has been described elsewhere; 67 therefore a brief description follows. Mixtures of $\mathrm{Ar}, \mathrm{O}_{2}$, and room temperature alcohol (2-propenol, 3-buten-2-ol, 3-buten-1-ol) (60 psi) were co-expanded using a pulsed molecular beam valve through a needle electrical discharge. ${ }^{68}$ The gas mixture passed through a skimmer, and the anions were accelerated to $1 \mathrm{keV}$. The ions were re-referenced to ground in a high voltage switch, ${ }^{69}$ then entered a Bakkerstyle time-of-flight mass spectrometer. ${ }^{70,71}$ Prior to colliding with a dual microchannel plate detector assembly, the anions of interest were selectively photodetached using the second (532 nm, $2.330 \mathrm{eV}$ ) and third (355 nm, $3.495 \mathrm{eV})$ harmonic outputs of a Nd:YAG laser (Continuum Surelite, $30 \mathrm{~Hz}$ ). Photoelectrons were extracted using a velocity map imaging lens system, ${ }^{72}$ and images were recorded on a dual microchannel plate-phosphor screen detector with a CCD camera. ${ }^{73,74}$ Three-dimensional PE velocity distributions are obtained using BASEX $^{75}$ and then converted to electron kinetic energy $\left(e^{-} \mathrm{KE}\right)$. Photoelectron spectra are plotted as a function of electron binding energy, $e^{-} \mathrm{BE}=h v-$ $e^{-} \mathrm{KE}$, which is independent of photon energy. Calibrations based on the well-known PE spectrum of $\mathrm{O}_{2}{ }^{-}$were performed for each complex. ${ }^{76}$ The pBASEX $\operatorname{code}^{77}$ was used to produce reconstructed images with fewer artifacts along the polarization axis line compared to BASEX, which has greater experimental noise but more reproducible velocity distributions.

PEI inherently records the photoelectron angular distributions (PADs) for all transitions. For a randomly oriented species, the differential cross section is given by ${ }^{78}$

$$
\frac{\partial \sigma}{\partial \Omega}=\frac{\sigma_{\text {total }}}{4 \pi}\left[1+\beta(E)\left(\frac{3}{2} \cos ^{2} \theta-\frac{1}{2}\right)\right],
$$

where $\sigma_{\text {total }}$ is the total photodetachment cross section, $\theta$ is the angle relative to the laser electric field polarization, and $\beta(\mathrm{E})$ is an electron-kinetic-energy-dependent asymmetry parameter. For low symmetry molecular detachment, $\beta$ cannot be used to definitively infer the nature of the molecular orbital associated with the detachment transition, but disparate PADs can be useful for discerning overlapping electronic transitions. Asymmetry parameters are approximated from

$$
\beta(E)=\frac{I_{0}-I_{90}}{\frac{1}{2} I_{0}+I_{90}}
$$

which gives $\beta=0$ for isotropic distributions (s-wave photoelectrons, typically detached from atomic $p$-like orbitals near the threshold), $\beta=-1$ for perpendicular transitions (typical of $s$ - and $d$-wave interference), and +2 for detachment for parallel transitions ( $p$-wave photoelectrons, typical of detachment from atomic $s$-like orbitals).

\section{B. Computational}

Multiple initial conformers of each anion and neutral alkenoxy radical complex were explored using the GAUSSIAN0979 suite for electronic structure calculations. Optimized structures were calculated using the Coulombattenuating method-Becke, 3-parameter, Lee, Yang, and Parr (CAM-B3LYP) ${ }^{80}$ functional with the aug-cc-pVTZ basis set as well as the second-order Møller-Plesset perturbation theory with the cc-pVDZ basis set followed by MP2/cc-pVTZ and MP2/aug-cc-pVTZ single point calculations. ${ }^{81}$ Frequency calculations were performed on optimized structures to verify that local minima were found. Adiabatic detachment energies (ADEs), which are measured experimentally, are calculated as the difference between the energies of the anion and one-electron accessible neutral states.

Time-dependent density functional theory (TDDFT) calculations were also performed on the neutral species calculated at the CAM-B3LYP level to determine the computationally predicted relative energy of the first excited state of each neutral radical. The excited state has the "hole" in the non-bonding $2 p$ orbital localized on the $\mathrm{O}$-atom that is doubly occupied in the ground state. The method was benchmarked with the ethoxy radical, for which the $\tilde{A}-\tilde{X}$ transition energy is known to be $360 \mathrm{~cm}^{-1} \cdot{ }^{55,61}$ The TDDFT calculations overestimated the $\tilde{A}-\tilde{X}$ splitting by $0.28 \mathrm{eV}$. We therefore draw only on qualitative trends in $\tilde{\mathrm{A}}-\tilde{\mathrm{X}}$ relative energies from the TDDFT results. To test the validity of the trends in excitation energies from TDDFT results, more expensive Equation of Motion-Coupled Cluster (EOM-CCSD) calculations using the aug-cc-pVDZ basis set were completed for the lowest energy conformers optimized with CAM-B3LYP calculations for each of the alkenoxy radicals and the ethoxy radical. This method is effective for treating electronically excited states and open shell species. ${ }^{82}$ The results, included in the supplementary material, show identical qualitative trends as the TDDFT results and systematically lie between the TDDFT and experimental results.

The analysis of the experimental spectra is facilitated by spectral simulations based on the calculated spectroscopic parameters using a home-written LabView program that treats vibrational wavefunctions as harmonic oscillator 
wavefunctions and assumes normal coordinates and parallel modes between the anion and neutral. In general, there is very little difference between the anion and neutral optimized structures, with modest activation of one or more $\sim 1400 \mathrm{~cm}^{-1}$ vibrational modes, so the approach is reasonable. A more detailed description of the code is available in Ref. 83.

\section{RESULTS}

\section{A. PEI spectra}

Figure 1 shows the PEI spectra of (a) 2-propenoxide, (b) 3buten-2-oxide, and (c) 3-buten-1-oxide anions obtained using

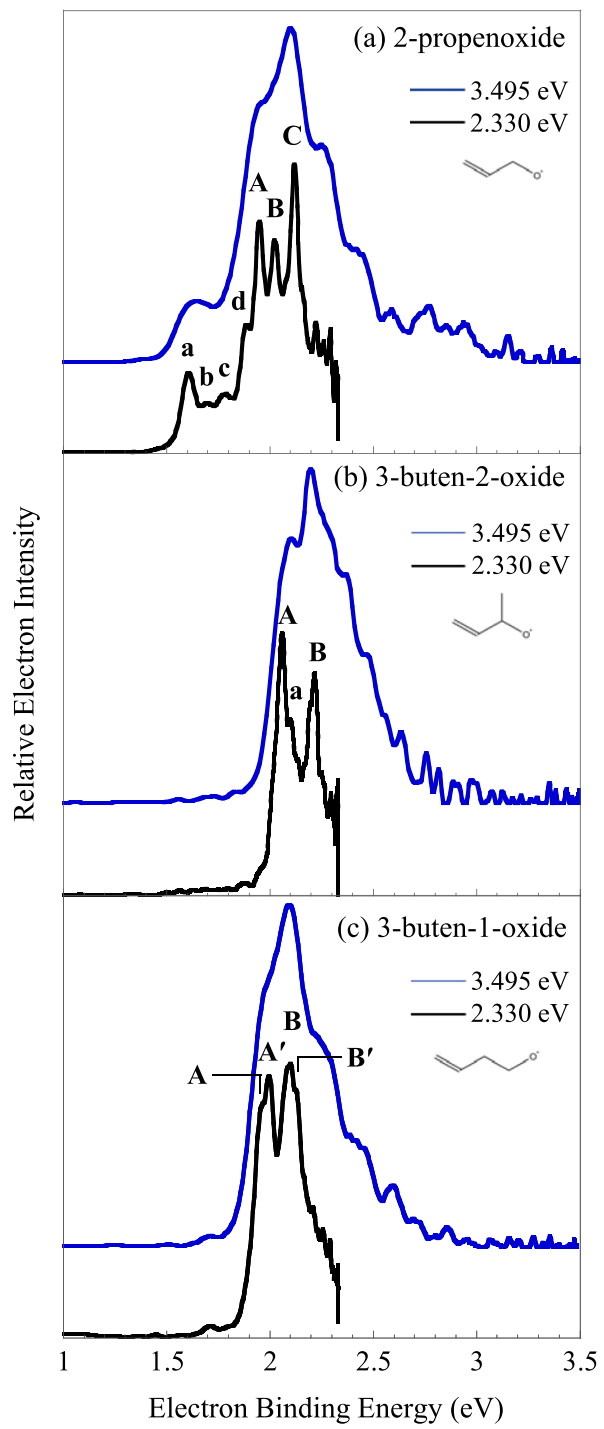

FIG. 1. PEI spectra of (a) 2-propenoxide, (b) 3-buten-2-oxide, and (c) 3-buten-1oxide measured using $2.330 \mathrm{eV}$ (black traces) and $3.495 \mathrm{eV}$ (blue traces) photon energies.
$2.330 \mathrm{eV}$ (black traces) and $3.495 \mathrm{eV}$ (blue traces) photon energies. Raw and reconstructed images are included in the supplementary material. All three spectra exhibit a qualitatively similar structure, in that the features appear at $e^{-} B E$ values around $2 \mathrm{eV}$, which is a typical electron affinity for alkoxy radicals. $^{36,57,59,62,63}$ The spectra obtained using $3.495 \mathrm{eV}$ exhibit a progression of shoulders on the higher $e^{-} \mathrm{BE}$ edge separated by approximately $1400 \mathrm{~cm}^{-1}-1450 \mathrm{~cm}^{-1}$. The spectra obtained using $2.330 \mathrm{eV}$ resolve more distinct features that do not appear to form a regularly spaced vibrational progression, suggesting closely overlapping transitions. For example, the irregularly shaped peaks A, $\mathbf{A}^{\prime}, \mathbf{B}$, and $\mathbf{B}^{\prime}$ labeled on the $2.330 \mathrm{eV}$ spectrum of 3-buten-1-oxide [Fig. 1(c)] are not members of the $1400 \mathrm{~cm}^{-1}$ progression evident in the $3.495 \mathrm{eV}$ spectrum tailing to higher $e^{-} \mathrm{BE}$. The transition energies of spectral features labeled in Fig. 1 are summarized in Table I.

Figure 2 shows the spectra of all three anions measured with $2.330 \mathrm{eV}$ photon energy on expanded scales and resolved in terms of parallel $\left(\theta=0^{\circ}\right)$ and perpendicular $\left(\theta=90^{\circ}\right)$ transitions relative to the laser polarization [Eq. (1)]. Spectra corresponding to $\theta=0^{\circ}$ and $\theta=90^{\circ}$ for the spectra measured with $3.495 \mathrm{eV}$ photon energy are provided in the supplementary material. The corresponding anisotropy parameters $[\beta$, Eq. (2)] are included in Table I. The PEI spectrum of 2-propenoxide [Figs. 1(a) and 2(a)] shows more clearly resolved features than that of the butenoxides, with three intense peaks labeled $\mathbf{A}$, $\mathbf{B}$, and $\mathbf{C}$, irregularly spaced between 1.95 and $2.12 \mathrm{eV}$, all with disparate PAD. Disparate PADs were observed in alkoxide detachment transitions to the $\tilde{X}$ and $\tilde{A}$ states of the alkoxy radicals by Lineberger and co-workers. ${ }^{62}$ In addition, there

TABLE I. Summary of transition energies and asymmetry parameters determined from the PEI spectra of the alkenoxy radical anions. Tabulated asymmetry parameters are affected by overlapping transitions with different PAD and have errors of \pm 0.1 . Vibrational modes follow the mode numbers from the Gaussian output files.

\begin{tabular}{|c|c|c|c|c|}
\hline Peak & $\begin{array}{c}\text { Transition } \\
\text { energy }(e V)\end{array}$ & $\begin{array}{c}\beta \\
2.330 \mathrm{eV}\end{array}$ & $\begin{array}{c}\beta \\
3.495 \mathrm{eV}\end{array}$ & $\begin{array}{c}\text { Tentative } \\
\text { assignment }\end{array}$ \\
\hline \multicolumn{5}{|c|}{ 2-Propenoxide } \\
\hline $\mathrm{C}$ & 2.12 & 0.2 & -0.2 & I $\tilde{A}^{2} \mathrm{~A}-\tilde{\mathrm{X}}^{1} \mathrm{~A}$ \\
\hline B & 2.02 & -0.1 & -0.3 & (Unassigned) \\
\hline $\mathbf{A}$ & 1.95 & -0.1 & -0.5 & I $\tilde{X}^{2} A-\tilde{X}^{1} A$ \\
\hline d & 1.88 & -0.1 & -0.5 & II $\tilde{A}^{2} \mathrm{~A}-\tilde{\mathrm{X}}^{1} \mathrm{~A}$ \\
\hline $\mathbf{c}$ & 1.78 & -0.3 & -0.7 & II $\tilde{\mathrm{X}}^{2} \mathrm{~A}-\tilde{\mathrm{X}}^{1} \mathrm{~A} 13_{0}^{1}$ \\
\hline $\mathbf{b}$ & 1.69 & -0.3 & -0.6 & II $\tilde{\mathrm{X}}^{2} \mathrm{~A}-\tilde{\mathrm{X}}^{1} \mathrm{~A} 5_{0}^{1}$ \\
\hline $\mathbf{a}$ & 1.60 & -0.6 & -0.6 & II $\tilde{\mathrm{X}}^{2} \mathrm{~A}-\tilde{\mathrm{X}}^{1} \mathrm{~A}$ \\
\hline \multicolumn{5}{|c|}{ 3-Buten-2-oxide } \\
\hline B & 2.21 & 0.1 & 0.6 & I $\tilde{A}^{2} \mathrm{~A}-\tilde{\mathrm{X}}^{1} \mathrm{~A}$ \\
\hline $\mathbf{a}$ & 2.10 & 0.3 & 0.6 & II $\tilde{X}^{2} A-\tilde{X}^{1} A$ \\
\hline A & 2.06 & 0.3 & 0.2 & $\mathbf{I} \tilde{X}^{2} \mathrm{~A}-\tilde{\mathrm{X}}^{1} \mathrm{~A}$ \\
\hline \multicolumn{5}{|c|}{ 3-Buten-1-oxide } \\
\hline $\mathbf{B}^{\prime}$ & 2.12 & 0.4 & 0.0 & I $\tilde{A}^{2} \mathrm{~A}-\tilde{X}^{1} \mathrm{~A}$ \\
\hline B & 2.09 & 0.2 & 0.0 & $\mathbf{I} \tilde{\mathrm{X}}^{2} \mathrm{~A}-\tilde{\mathrm{X}}^{1} \mathrm{~A}$ \\
\hline $\mathbf{A}^{\prime}$ & 2.00 & 0.5 & -0.2 & II $\tilde{\mathrm{A}}^{2} \mathrm{~A}-\tilde{\mathrm{X}}^{1} \mathrm{~A}$ \\
\hline $\mathbf{A}$ & 1.96 & 0.3 & -0.3 & II $\tilde{X}^{2} A-\tilde{X}^{1} A$ \\
\hline
\end{tabular}




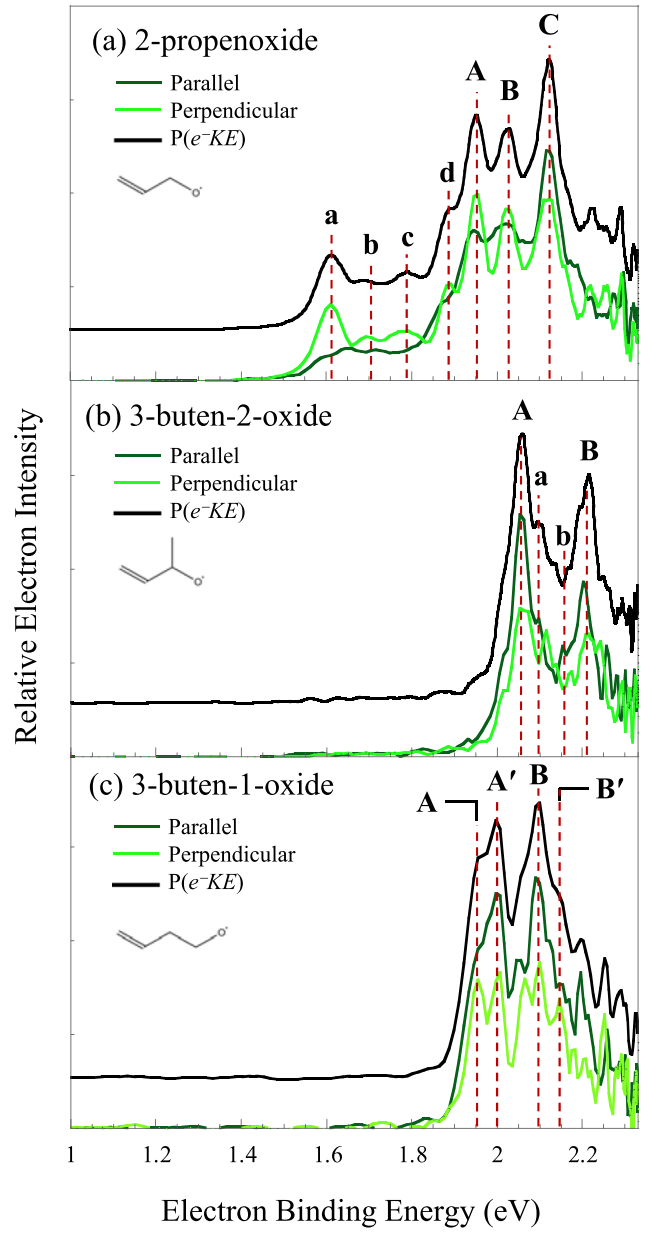

FIG. 2. Spectra of (a) 2-propenoxide, (b) 3-buten-2-oxide, and (c) 3-buten-1oxide measured using $2.330 \mathrm{eV}$ resolved into parallel (dark green traces) and perpendicular (light green traces) PADs. PE spectra are overlaid in black.

are less intense but distinct features (a-d) from $1.6 \mathrm{eV}$ to $1.9 \mathrm{eV}$.

Overall, the PADs of the features in the 2-propenoxide spectrum are more perpendicular than those in the other spectra. The most intense feature in the PE spectrum of the allylic 3-buten-2-oxide [Figs. 1(b) and 2(b)], labeled A, is at $2.05 \mathrm{eV}$ and is more intense in the parallel spectrum. Peak B at approximately $2.2 \mathrm{eV}$ is non-Lorentzian, and it can be seen from comparing the parallel and perpendicular spectra that the lower $e^{-} \mathrm{BE}$ edge of the peak is more parallel, while the higher $e^{-} \mathrm{BE}$ edge of the peak is more perpendicular. This effect is borne out in the PADs of the same features in the spectrum obtained using $3.495 \mathrm{eV}$ photon energy (supplementary material), in which the features above $2.25 \mathrm{eV}$ have nearly isotropic PAD, while below $2.25 \mathrm{eV}$, the features approach $\beta=0.6$.

The 3-buten-1-oxide spectrum [Figs. 1(c) and 2(c)] appears to be dominated by two intense features, also with non-Lorentzian profiles, and spaced by approximately $0.11 \mathrm{eV}$ $\left(890 \mathrm{~cm}^{-1}\right)$. It is evident from Fig. 2(c) that the features labeled $\mathbf{A}$ and $\mathbf{A}^{\prime}$ can be attributed to close-lying transitions with different PADs, separated by $0.04(1) \mathrm{eV}$, which is comparable to the $\tilde{\mathrm{A}}-\tilde{\mathrm{X}}$ splitting observed in alkoxy radicals. ${ }^{55}$ Peaks $\mathbf{B}$ and $\mathbf{B}^{\prime}$ have similar PADs. The relative A-B intensity in the spectrum generated from the perpendicular spectrum is different from the relative intensity in the parallel spectrum, indicating that peaks $\mathbf{A}$ (or $\mathbf{A}^{\prime}$ ) and $\mathbf{B}$ (or $\mathbf{B}^{\prime}$ ) are not members of a vibrational progression. The slices of the reconstructed images at $10^{\circ}$ increments for all three alkenoxides are available in the supplementary material.

\section{B. Computational results}

To assess the potential contribution of multiple energetically competitive conformers to the spectra, calculations on different conformers for both the anion and neutral species were performed. Figure 3 shows the molecular structures of the anionic alkenoxide species for (a) 2-propenoxide, (b) 3-buten-2-oxide, and (c) 3-buten-1-oxide calculated using CAM-B3LYP/aug-cc-pVTZ. Transition states between the structures are included in the supplementary material; barriers are calculated to be on the order of $0.12-0.26 \mathrm{eV}$, with 2-propenoxide having the highest barrier separating the two conformers found. Neutral conformers with very similar structures to the anionic conformers also converged, and

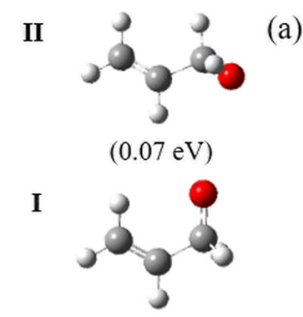

$(0.00 \mathrm{eV})$

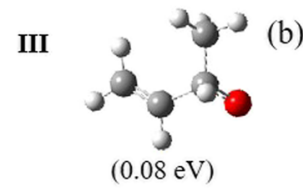

II

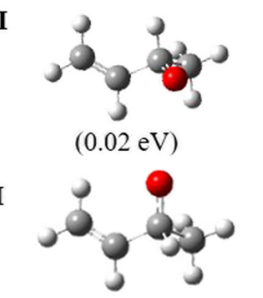

$(0.00 \mathrm{eV})$ (c)

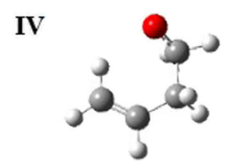

$(0.13 \mathrm{eV})$

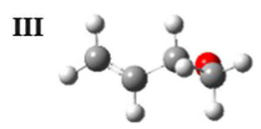

$(0.08 \mathrm{eV})$

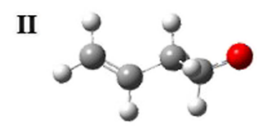

$(0.04 \mathrm{eV})$

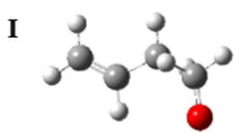

$(0.00 \mathrm{eV})$
FIG. 3. Optimized structures of the (a) 2-propenoxide, (b) 3-buten-2-oxide, and (c) 3-buten-1-oxide anions calculated using DFT. The energy relative to the most stable anion conformer is shown in parentheses below each structure. 
TABLE II. Summary of computational results, including zero-point correct energies, $C=C$ and $C-O$ bond distances are determined from CAM-B3LYP/aug-cC-pVTZ optimized structures, and term energy of the $\tilde{A}^{2} A$ states from TDDFT calculations. Relative energies of analogous conformers optimized with the MP2/cc-pVDZ followed by MP2/aug-cc-pVTZ single point calculations are included for comparison.

\begin{tabular}{|c|c|c|c|c|c|c|c|}
\hline Conformer & $\begin{array}{l}\text { CAM B3LYP } \\
\text { relative } \\
\text { energy }(\mathrm{eV})\end{array}$ & $\begin{array}{l}\mathrm{ADE} \\
(\mathrm{eV})\end{array}$ & $\begin{array}{c}\text { TDDFT } \\
\tilde{A}^{2} \mathrm{~A} \text { term } \\
\text { energy }(\mathrm{eV})\end{array}$ & $\begin{array}{c}r(C=C) \\
(\AA)\end{array}$ & $\begin{array}{c}r(\mathrm{C}-\mathrm{O}) \\
(\AA)\end{array}$ & $\begin{array}{c}\text { MP2/aug-cc-pVTZ } \\
\text { SP relative } \\
\text { energy }(\mathrm{eV})\end{array}$ & $\begin{array}{l}\mathrm{ADE} \\
(\mathrm{eV})\end{array}$ \\
\hline \multicolumn{8}{|l|}{$\begin{array}{l}\text { 2-Propenoxy } \\
\text { neutral }\end{array}$} \\
\hline II & 1.86 & 1.78 & 0.43 & 1.320 & 1.362 & 2.33 & 2.25 \\
\hline I & 1.84 & 1.84 & 0.39 & 1.319 & 1.356 & 2.33 & 2.33 \\
\hline \multicolumn{8}{|l|}{ 2-Propenoxide } \\
\hline II & 0.07 & & & 1.328 & 1.339 & 0.08 & \\
\hline I & 0.00 & & & 1.326 & 1.324 & 0.00 & \\
\hline \multicolumn{8}{|l|}{$\begin{array}{l}\text { 3-Buten-2-oxy } \\
\text { neutral }\end{array}$} \\
\hline III & 1.95 & 1.87 & 0.41 & 1.320 & 1.369 & 2.48 & 2.39 \\
\hline II & 1.93 & 1.91 & 0.38 & 1.319 & 1.371 & 2.58 & 2.55 \\
\hline I & 1.93 & 1.93 & 0.35 & 1.319 & 1.363 & 2.45 & 2.45 \\
\hline \multicolumn{8}{|l|}{ 3-Buten-2-oxide } \\
\hline III & 0.08 & & & 1.329 & 1.342 & 0.09 & \\
\hline II & 0.02 & & & 1.328 & 1.340 & 0.03 & \\
\hline $\mathbf{I}$ & 0.00 & & & 1.324 & 1.328 & 0.00 & \\
\hline \multicolumn{8}{|l|}{$\begin{array}{l}\text { 3-Buten-1-oxy } \\
\text { neutral }\end{array}$} \\
\hline IV & 1.88 & 1.75 & 0.37 & 1.321 & 1.362 & 2.31 & 2.20 \\
\hline III & 1.84 & 1.76 & 0.33 & 1.320 & 1.360 & 2.28 & 2.20 \\
\hline II & 1.82 & 1.78 & 0.33 & 1.321 & 1.359 & 2.22 & 2.19 \\
\hline I & 1.82 & 1.82 & 0.33 & 1.321 & 1.360 & 2.30 & 2.30 \\
\hline \multicolumn{8}{|l|}{ 3-Buten-1-oxide } \\
\hline IV & 0.13 & & & 1.325 & 1.335 & 0.11 & \\
\hline III & 0.08 & & & 1.325 & 1.325 & 0.08 & \\
\hline II & 0.04 & & & 1.328 & 1.326 & 0.03 & \\
\hline I & 0.00 & & & 1.328 & 1.330 & 0.0 & \\
\hline
\end{tabular}

like-neutral conformers were used when calculating ADEs. Table II summarizes the CAM-B3LYP relative energies, $\mathrm{C}-\mathrm{O}$ and $\mathrm{C}=\mathrm{C}$ bond lengths, and TDDFT $\tilde{\mathrm{A}}-\tilde{\mathrm{X}}$ term energies as well as the relative energies from MP2/aug-cc-pVTZ single point calculations. Note that while all conformers for a given neutral are predicted to be very close in energy by both the CAM-B3LYP and MP2 methods, the methods disagree as to the relative energy of the conformers. However, there is very close agreement on the relative energies of the conformers of the anion. The ADE values resulting from the MP2 calculations are modestly higher than the observed transition energies, while the CAM-B3LYP ADE values overlap with the observed transition energies. Given the narrow energy range for the conformers shown, we could anticipate multiple species populating the ion beam.

A general result is that the trend in calculated ADE values is consistent with the observed relative energies of the most intense features observed in the spectra of the three species, with 3-buten-2-oxide conformers predicted to have slightly higher electron binding energies than the other two species. In addition, the neutral conformers for each of these species are closer in energy than the corresponding anions. As a result, the predicted ADE values are lower for less stable conformers, uniformly so for the CAM-B3LYP results, though less consistently in the MP2-calculated ADE values. TDDFTcalculated energies for the $\tilde{A}$ states, as noted in Sec. II B, are presumed to overestimate the true value by tenths of eV. However, if the trends in excited state energies are correct, then the $\tilde{A}$ state term energies increase per 3-buten-1-oxy $<3$ buten-2-oxy $<2$-propenoxy radicals. In addition, the $\tilde{A}$ state term energies are higher for higher energy conformers for each molecule, though the effect is more pronounced for the allylic oxy radicals.

\section{ANALYSIS AND DISCUSSION}

The definitive assignment of the spectra is complicated by close-lying neutral states and the presence of multiple anion 
conformers. In this section, we systematically consider the PADs of different features in the spectra, the general trends in calculated binding energies and $\tilde{A}$ state term energies, and the predicted spectral profiles based on simulations generated from calculated spectroscopic parameters. The approach is to identify features in the spectra with more isotropic or perpendicular PADs, which, based on previous studies by Lineberger and co-workers, ${ }^{62}$ would more likely be assigned to $\tilde{X}^{2} \mathrm{~A}-\tilde{\mathrm{X}}^{1} \mathrm{~A}$ transitions for any given conformer of each alkenoxide, and then map the spectral simulations generated for these transitions based on computational results to evaluate for agreement. We then determine whether remaining features could be attributed to other conformers or the $\tilde{\mathrm{A}}^{2} \mathrm{~A}-\tilde{\mathrm{X}}^{1} \mathrm{~A}$ transitions.

\section{A. 2-propenoxide}

The PE spectrum of 2-propenoxide has two likely origin features that are more intense in the perpendicular spectrum at approximately $1.60 \mathrm{eV}$ (peak a) and $1.95 \mathrm{eV}$ (peak A), as shown in Fig. 2(a). For the two anionic conformers found computationally [Fig. 3(a)], both the CAM-B3LYP and MP2 calculations predict lower ADE values associated with the detachment of the higher energy anion conformer (II). We therefore consider assigning peak $\mathbf{A}$ to the $\tilde{\mathrm{X}}^{2} \mathrm{~A}-\tilde{\mathrm{X}}^{1} \mathrm{~A}$ transition of conformer $\mathbf{I}$, and peak a to the $\tilde{\mathrm{X}}^{2} \mathrm{~A}-\tilde{\mathrm{X}}^{1} \mathrm{~A}$ transition of conformer II. Figure 4(a) shows the simulations based on the $\tilde{X}^{2} A-\tilde{X}^{1} A$ transition of conformer I with the origin set to the position of peak A, $1.95 \mathrm{eV}$ (blue trace, calculated origin is $1.84 \mathrm{eV}$ ), and the $\tilde{\mathrm{X}}^{2} \mathrm{~A}-$ $\tilde{\mathrm{X}}^{1} \mathrm{~A}$ transition of conformer II with the origin set to the position of peak a, $1.60 \mathrm{eV}$ (red trace, calculated origin is $1.78 \mathrm{eV}$ ), summed (solid black trace) and superimposed on the $2.330 \mathrm{eV}$ experimental spectrum (dotted black trace). The dominant progression in the simulation of conformer I has contributions from overlapping progressions and combinations of $1337 \mathrm{~cm}^{-1}$ and $1399 \mathrm{~cm}^{-1}$ modes, which are associated with the rocking and scissor motion of the $\mathrm{H}$-atoms bound to $\mathrm{C}$, the atom to which the $\mathrm{O}$-atom is also bound. The simulation for conformer II also shows a progression in the $\mathrm{CH}_{2}$ rocking motion which is active in addition to an $801 \mathrm{~cm}^{-1}$ twist motion progression associated with the $\mathrm{O}-\mathrm{C}-\mathrm{C}-\mathrm{C}$ backbone. We note here that a modest decrease in the normal coordinate displacement for this mode (from the calculated value of $0.33 \mathrm{amu}^{1 / 2}$ $\AA$ shown to $0.21 \mathrm{amu}^{1 / 2} \AA$ ) results in a simulation that matches the observed series of peaks, $\mathbf{a}, \mathbf{b}$, and $\mathbf{c}$. Simulation parameters and the simulation assuming the adjusted displacement for the twist mode are available in the supplementary material.

By surveying the remaining signal in the PE spectrum obtained using $2.330 \mathrm{eV}$, it is evident that peaks $\mathbf{B}$ and $\mathbf{C}$, along with shoulder $\mathbf{d}$, are not accounted for by the $\tilde{X}^{2} \mathrm{~A}-\tilde{\mathrm{X}}^{1} \mathrm{~A}$ simulations for conformers I and II. The position of peak $\mathbf{C}$ coincides with the $v=1$ level in the main progression for conformer I but not the intensity, and the disparate PAD of peaks $\mathbf{A}$ and $\mathbf{C}$ raises the possibility that $\mathbf{C}$ is the origin of the $\tilde{A}^{2} \mathrm{~A}-\tilde{\mathrm{X}}^{1} \mathrm{~A}$ transition of conformer $\mathbf{I}$. In addition, we consider the possibility that shoulder $\mathbf{d}$ is the origin of the $\tilde{A}^{2} \mathrm{~A}-\tilde{\mathrm{X}}^{1} \mathrm{~A}$ transition of conformer II. Because we do not have
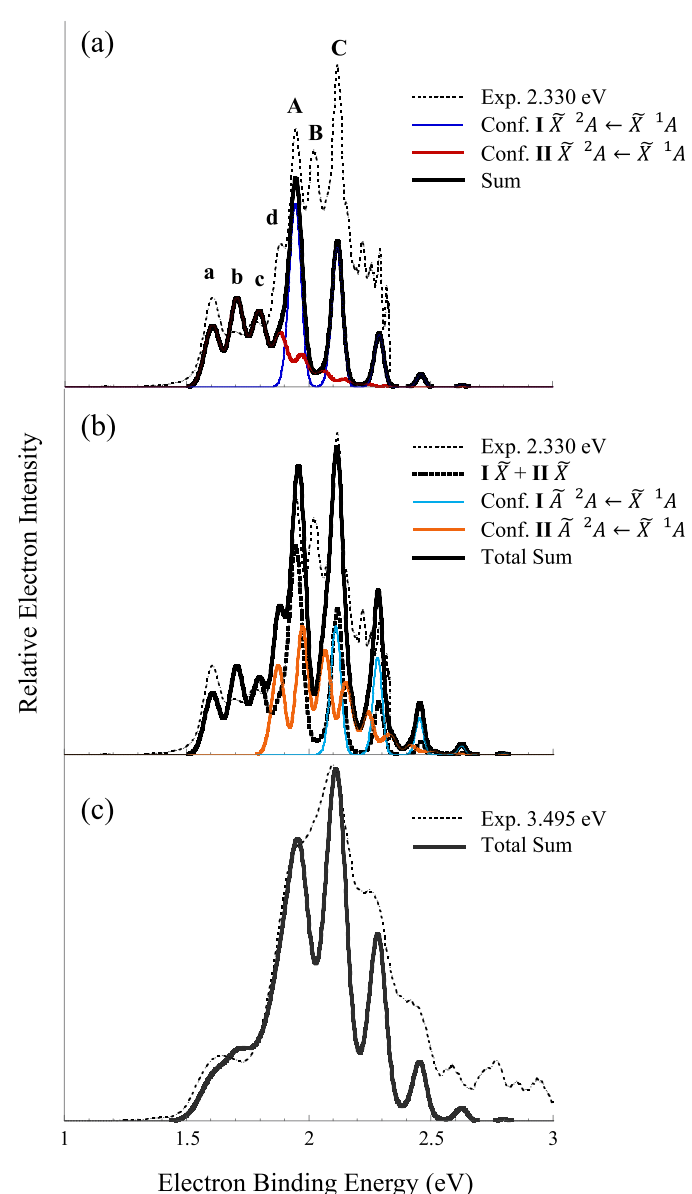

FIG. 4. (a) Simulations based on the $\tilde{X}^{2} A \leftarrow \tilde{X}^{1} A$ transition for conformers (blue) and II (red) of 2-propenoxide, along with the sum (solid black) superimposed on the PE spectrum measured with $2.330 \mathrm{eV}$ (dotted trace). (b) The sum of simulations shown in (a) along with $\tilde{\mathrm{A}}^{2} \mathrm{~A} \leftarrow \tilde{\mathrm{X}}^{1} \mathrm{~A}$ transitions for conformer I (light blue) and II (orange). (c) Sum of all four simulations generated with peak widths broadened (solid black trace) and superimposed on the spectrum obtained with $3.495 \mathrm{eV}$ photon energy (dotted black trace). Simulation parameters are in the supplementary material.

optimized structures of the $\tilde{\mathrm{A}}^{2} \mathrm{~A}$ states from the DFT calculations, we assumed the same simulation parameters as above; we note that although vibrational progressions in the two close-lying electronic transitions of alkoxides had subtle differences, they generally showed comparable progressions in $\sim 1400 \mathrm{~cm}^{-1}$ modes. ${ }^{62}$ Figure 4(b) shows both the sum of the two $\tilde{X}^{2} \mathrm{~A}-\tilde{\mathrm{X}}^{1} \mathrm{~A}$ transitions (heavy dotted black trace) along with the two $\tilde{\mathrm{A}}^{2} \mathrm{~A}-\tilde{\mathrm{X}}^{1} \mathrm{~A}$ simulations for conformers I (light blue trace) and II (orange trace) and the subsequent sum of all four simulations (solid black trace). Peak B is still unassigned, which may indicate an additional conformer that is not identified in the calculations. However, by superimposing the sum of the simulations after being broadened to reflect the change in resolution onto the spectrum obtained with $3.495 \mathrm{eV}$ in Fig. 4(c), it becomes evident that the general features of the spectrum are accounted for. 
Assigning peak $\mathbf{C}$ to the origin of the $\tilde{\mathrm{A}}^{2} \mathrm{~A}-\tilde{\mathrm{X}}^{1} \mathrm{~A}$ transition of conformer I gives an $\tilde{\mathrm{A}}^{2} \mathrm{~A}$ term energy of $0.17 \pm 0.02 \mathrm{eV}$ $\left(1370 \pm 160 \mathrm{~cm}^{-1}\right)$, and, likewise, assigning $\mathbf{d}$ to the $\tilde{\mathrm{A}}^{2} \mathrm{~A}-\tilde{\mathrm{X}}^{1} \mathrm{~A}$ transition of conformer II gives an $\tilde{\mathrm{A}}^{2} \mathrm{~A}$ term energy of 0.28 $\pm 0.03 \mathrm{eV}\left(2258 \pm 240 \mathrm{~cm}^{-1}\right)$. The TDDFT results predict on average slightly larger $\tilde{\mathrm{A}}^{2} \mathrm{~A}-\tilde{\mathrm{X}}^{2} \mathrm{~A}$ energy differences for the 2-propenoxy radical compared to the butenoxy radicals, with the splitting being slightly larger for conformer II $(0.43 \mathrm{eV})$ relative to conformer $\mathbf{I}(0.39 \mathrm{eV})$. While these assignments are tentative, they are also reasonable taking into account the PADs of features in the spectrum and the appearance and relative electron binding energies associated with the transitions to the ground states of both conformers. Note that we cannot unambiguously assign an electron affinity, since the difference in binding energies of the two conformers raises the possibility that conformer II is lower in energy on the neutral conformer surface.

\section{B. 3-buten-2-oxide}

The PE spectrum of 3-buten-2-oxide has the simplest spectral profile of the three alkenoxides presented here. Based on the PADs in both the spectra obtained using $2.330 \mathrm{eV}$ [Fig. 2(b)] and $3.495 \mathrm{eV}$ (supplementary material) there are two minimally distinct transitions contributing to the spectrum. Unlike the 2-propenoxide spectrum, the lowest energy feature, peak $\mathbf{A}$, is more intense in the parallel spectrum. Figure 5 (a) shows the simulation based on the $\tilde{X}^{2} A-\tilde{X}^{1} A$ transition of conformer I with the origin set to $2.057 \mathrm{eV}$ (blue trace, calculated origin is $1.93 \mathrm{eV}$ ) superimposed on the PE spectrum obtained using $2.330 \mathrm{eV}$ photon energy (dotted trace). Again, the vibrational features are overlapping and combination progressions are prevalent; this is especially seen in the $\sim 1400 \mathrm{~cm}^{-1} \mathrm{H}$-wagging motion, particularly involving the $\mathrm{H}$-atom bound to $\mathrm{C} 2$, which also binds to the $\mathrm{O}$-atom. What is immediately evident is that the position of peak $\mathbf{B}$ is lower in electron binding energy than the $v=1$ level of the vibrational progression. We therefore consider the possibility that $\mathbf{B}$ is the origin of the $\tilde{A}^{2} \mathrm{~A}-\tilde{\mathrm{X}}^{1} \mathrm{~A}$ transition of conformer $\mathbf{I}$. Using the same spectroscopic parameters calculated for the $\tilde{X}^{2} A-\tilde{X}^{1} A$ transition, but with the origin set to $2.185 \mathrm{eV}$, we were able to reproduce the shape of peak $\mathbf{B}$. The sum of the two simulations is shown in Fig. 5(b) (solid black trace) superimposed on the $3.495 \mathrm{eV}$ spectrum (dotted trace) which shows more of the overall manifold of overlapping states. Based on the relative energies, the term energy of $\widetilde{A}^{2} \mathrm{~A}$ is $0.13 \pm 0.02 \mathrm{eV}(1050$ $\pm 160 \mathrm{~cm}^{-1}$ ).

Despite invoking lower resolution in the $\tilde{X}^{2} \mathrm{~A}-\tilde{\mathrm{X}}^{1} \mathrm{~A}$ and $\tilde{A}^{2} \mathrm{~A}-\tilde{\mathrm{X}}^{1} \mathrm{~A}$ simulations shown in Fig. $5(\mathrm{~b})$, the sum does not account for much of the shoulder progression on the high $e^{-} \mathrm{BE}$ side of the manifold of transitions, and, indeed, the signal between peaks $\mathbf{A}$ and $\mathbf{B}$ appears more intense in the $3.495 \mathrm{eV}$ spectrum than in the $2.330 \mathrm{eV}$ spectrum, which may be due to threshold effects. We note that the spectrum has been acquired under different source conditions, and the profile of this spectrum is reproducible (supplementary material). It is possible that an additional pair of $\tilde{X}^{2} \mathrm{~A}-\tilde{\mathrm{X}}^{1} \mathrm{~A}$ and $\tilde{\mathrm{A}}^{2} \mathrm{~A}-\tilde{\mathrm{X}}^{1} \mathrm{~A}$ transitions is contributing to the spectrum; in the case of

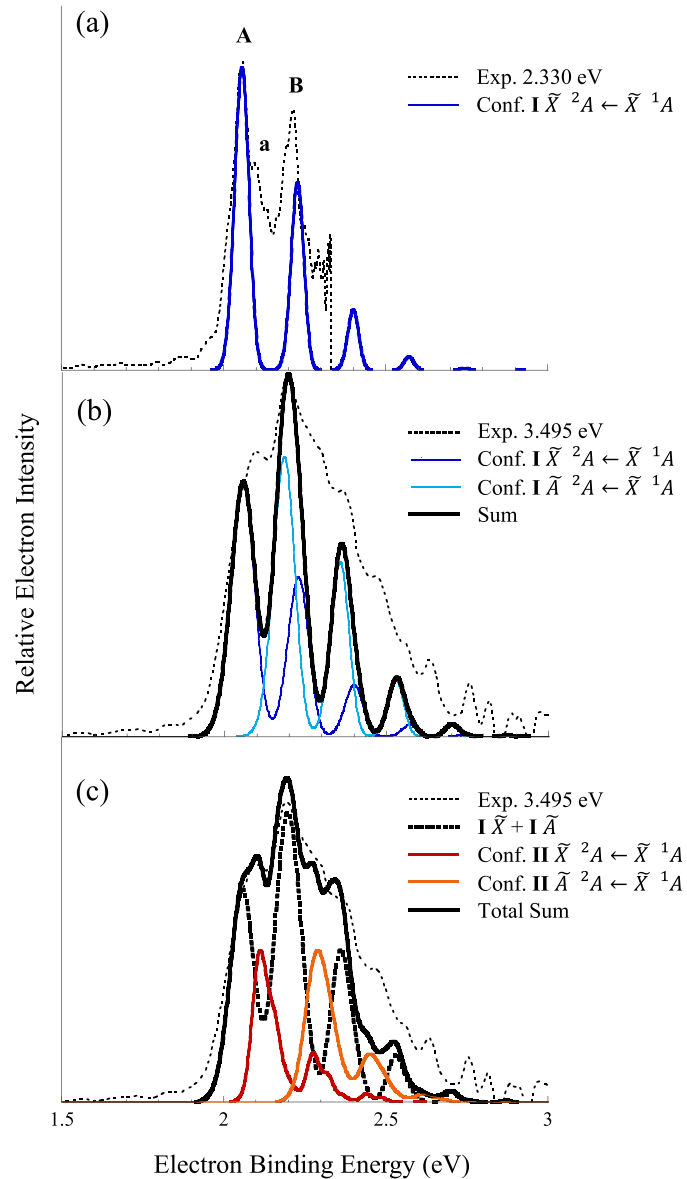

FIG. 5. (a) Simulation of the $\tilde{X}^{2} \mathrm{~A} \leftarrow \tilde{\mathrm{X}}^{1} \mathrm{~A}$ transition of conformer I of 3 buten-2-oxide (blue) superimposed on the PE spectrum measured using 2.330 $\mathrm{eV}$ (dotted black trace). (b) $\tilde{\mathrm{X}}^{2} \mathrm{~A} \leftarrow \tilde{\mathrm{X}}^{1} \mathrm{~A}$ broadened (blue trace), along with the $\tilde{\mathrm{A}}^{2} \mathrm{~A} \leftarrow \tilde{\mathrm{X}}^{1} \mathrm{~A}$ simulation (light blue trace) and their sum (solid black trace) superimposed onto the PE spectrum measured using $3.495 \mathrm{eV}$ photon energy (dotted black trace). (c) Simulations based on conformer II (red and orange traces) with the sum of conformer I simulations (heavy dotted black trace) and the total sum (solid black trace) superimposed on the $3.495 \mathrm{eV}$ spectrum (light dotted black trace) Simulation parameters are in the supplementary material.

3-buten-2-oxide, conformer II, which is higher in energy than conformer $\mathbf{I}$, is predicted to have a higher binding energy at the MP2 level (Table I). We therefore set the origin of the conformer II $\tilde{\mathrm{X}}^{2} \mathrm{~A}-\tilde{\mathrm{X}}^{1} \mathrm{~A}$ simulation at $2.110 \mathrm{eV}$ [red trace, Fig. 5(c)], which coincides with peak a, and a second simulation invoking the same parameters to an origin of $2.28 \mathrm{eV}$ [orange trace, Fig. 5(c)]. Summing these two simulations with the conformer I simulations [solid black trace, Fig. 5(c)] does give better agreement with the observed spectrum. While we cannot definitively assert that two conformers contribute to the spectrum, it is possible. Furthermore, the binding energies $(2.06 \mathrm{eV}$ and $2.11 \mathrm{eV})$ are in reasonable agreement with calculated values $(1.93 \mathrm{eV}$ and $1.91 \mathrm{eV}$, respectively, per CAMB3LYP; $2.45 \mathrm{eV}$ and $2.55 \mathrm{eV}$, respectively, per MP2; Table II). 
Simulation parameters are summarized in the supplementary material.

\section{3-buten-1-oxide}

The spectra of 3-buten-1-oxide and 3-buten-2-oxide obtained using $3.495 \mathrm{eV}$ are very similar in profile. However, the lower photon energy spectra are different in profile, and the PADs in both the $3.495 \mathrm{eV}$ (supplementary material) and $2.330 \mathrm{eV}$ spectra [Figs. 2(b) and 2(c)] are quite different. In particular, the signal labeled $\mathbf{A}^{\prime}$ is more parallel than the shoulder labeled $\mathbf{A}$, while $\mathbf{B}$ and $\mathbf{B}^{\prime}$ have similar PAD, the latter being modestly less isotropic. The $3.495 \mathrm{eV}$ spectrum shows more definitively that $\mathbf{A}$ and $\mathbf{B}$ are more perpendicular, with $\mathbf{A}^{\prime}$ and $\mathbf{B}^{\prime}$ being more parallel. Given the previous results on the disparate PADs for $\tilde{X}^{2} A-\tilde{X}^{1} A$ and $\tilde{A}^{2} A-\tilde{X}^{1} A$ transitions for primary alkoxides, we consider the possibility that peaks $\mathbf{A}$ and $\mathbf{A}^{\prime}$ are the $\tilde{X}^{2} \mathrm{~A}-\tilde{\mathrm{X}}^{1} \mathrm{~A}$ and $\tilde{\mathrm{A}}^{2} \mathrm{~A}-\tilde{\mathrm{X}}^{1} \mathrm{~A}$ transitions associated with the lower binding energy conformer II, while peaks $\mathbf{B}$ and $\mathbf{B}^{\prime}$ are the $\tilde{X}^{2} A-\tilde{X}^{1} A$ and $\tilde{A}^{2} \mathrm{~A}-\tilde{\mathrm{X}}^{1} \mathrm{~A}$ transitions associated with conformer $\mathbf{I}$. Both the CAM-B3LYP and MP2 calculations predict a higher binding energy for the lower energy conformer I (Table II), meaning that of the four transitions evident in the spectrum the feature at the lowest $e^{-} \mathrm{BE}$ (peak A) would be associated with conformer II.

Figure 6(a) shows a simulation based on the $\tilde{\mathrm{X}}^{2} \mathrm{~A}-\tilde{\mathrm{X}}^{1} \mathrm{~A}$ transition of conformer II that invokes $\mathrm{C} 1-\mathrm{H}$ atom scissor and wag modes $\left(1362 \mathrm{~cm}^{-1}\right.$ and $\left.1398 \mathrm{~cm}^{-1}\right)$ with the origin set to coincide with peak $\mathbf{A}$ at $1.94 \mathrm{eV}$ (red trace, calculated value is $1.78 \mathrm{eV})$. To approximate the $\tilde{\mathrm{A}}^{2} \mathrm{~A}-\tilde{\mathrm{X}}^{1} \mathrm{~A}$ transition, the same conformer II spectroscopic parameters were used, with the origin set to $1.995 \mathrm{eV}$ to align with peak $\mathbf{A}^{\prime}$ [Fig. 6(a), orange trace]. The sum of these two simulations is shown as the heavy black trace. It is clear that peaks $\mathbf{B}$ and $\mathbf{B}^{\prime}$, along with the higher $e^{-} \mathrm{BE}$ signal, are not a part of the broad, $\sim 1400 \mathrm{~cm}^{-1}$ progression originating from peaks $\mathbf{A}$ and $\mathbf{A}^{\prime}$. The simulation of the conformer $\mathbf{I} \tilde{X}^{2} \mathrm{~A}-\tilde{\mathrm{X}}^{1} \mathrm{~A}$ transition, shown as the dark blue trace on Fig. 6(b), is similar in profile and is also dominated by a combination of two modes involving the scissor $\left(1350 \mathrm{~cm}^{-1}\right)$ and wagging motion $\left(1400 \mathrm{~cm}^{-1}\right)$ of $\mathrm{C} 1 \mathrm{H}$-atoms. Set to an origin of $2.065 \mathrm{eV}$ (calculated origin is $1.82 \mathrm{eV}$ ), we note here that $\mathbf{B}^{\prime}$, which has comparable PAD to $\mathbf{A}$, has some contributions from the overlapping transition to the $v=1$ level of the conformer II $\tilde{X}^{2} \mathrm{~A}$ state. This feature could include contributions from the conformer I $\tilde{A}^{2} \mathrm{~A}-\tilde{\mathrm{X}}^{1} \mathrm{~A}$ transition. Figure $6(\mathrm{~b})$ (light blue trace) shows the corresponding simulation with the origin set to $2.11 \mathrm{eV}$ (the calculated origin is $2.15 \mathrm{eV}$ ) and otherwise identical parameters to the $\tilde{\mathrm{X}}^{2} \mathrm{~A}-\tilde{\mathrm{X}}^{1} \mathrm{~A}$ transition of conformer $\mathbf{I}$.

The sum of all four simulations (heavy black trace) is superimposed on the lower resolution PE spectra in Fig. 6(c). These assignments give an $\tilde{\mathrm{A}}^{2} \mathrm{~A}$ term energy of $0.05 \pm 0.02 \mathrm{eV}$ $\left(400 \pm 160 \mathrm{~cm}^{-1}\right)$ for both conformers, which is very close to the term energy for primary butoxy radicals. ${ }^{55}$ Alternative assumptions, e.g., peaks $\mathbf{A}$ and $\mathbf{B}$ assigned to the $\tilde{\mathrm{X}}^{2} \mathrm{~A}-$ $\tilde{X}^{1} \mathrm{~A}$ and $\tilde{\mathrm{A}}^{2} \mathrm{~A}-\tilde{\mathrm{X}}^{1} \mathrm{~A}$ transitions, respectively, of the lower
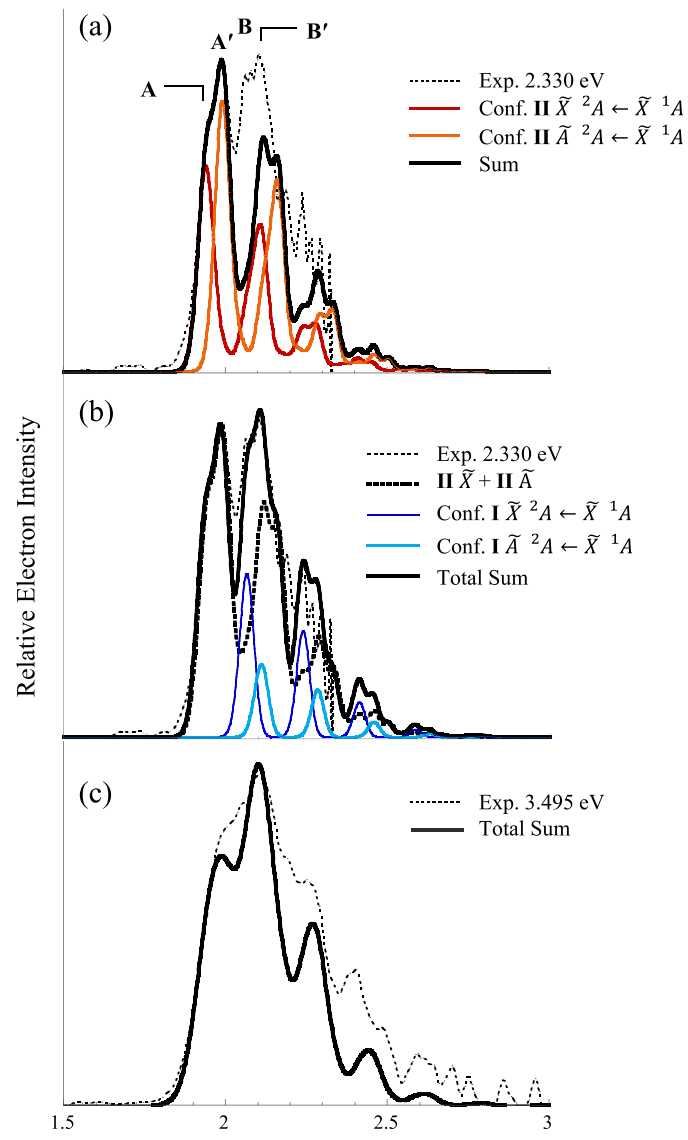

Electron Binding Energy $(\mathrm{eV})$

FIG. 6. (a) Simulations based on conformer II of 3-buten-1-oxide (red and orange traces) and the sum (solid black trace) superimposed on the $2.330 \mathrm{eV}$ PE spectrum (dotted black trace). (b) Simulations based on conformer I (dark and light blue traces) along with the sum of conformer II simulations (dotted black trace), the total sum of simulations (solid black trace), and the experimental spectrum (light dotted black trace). (c) The sum of all four simulations, broadened (solid black trace) superimposed on the $3.495 \mathrm{eV} P E$ spectrum (thin dotted trace). Simulation parameters are in the supplementary material.

binding energy conformer $\mathbf{I I}$ and peaks $\mathbf{A}^{\prime}$ and $\mathbf{B}^{\prime}$ associated with the analogous transitions originating from conformer I would yield an $\tilde{A}^{2} \mathrm{~A}$ term energy of $0.13 \pm 0.02 \mathrm{eV}$ $\left(1010 \pm 160 \mathrm{~cm}^{-1}\right)$ for both conformers. Either is plausible, though the former assignment is more consistent with the PADs.

\section{Trends in electronic structures and PAD}

Previous studies on saturated alkoxy radicals and photodetachment studies on alkoxide anions showed that, in general, the term energy of the first excited state $\left(\tilde{\mathrm{A}}^{2} \mathrm{~A}\right)$ decreased with increasing chain length for primary alkoxides. For a given chain length, the excitation energy is lower for secondary than primary alkoxy radicals. In the cur- 
rent study, the chain length trend holds; however, closer proximity of the oxy group to the $\pi$ bond appears to increase the $\tilde{\mathrm{A}}^{2} \mathrm{~A}$ state term energy. That is, the 2-propenoxy $\tilde{\mathrm{A}}^{2} \mathrm{~A}$ term energy for both conformers is higher than the 3-buten-2oxy and 3-buten-1-oxy $\tilde{A}^{2} \mathrm{~A}$ term energies. However, amongst the two butenoxy radicals, the latter has the lowest $\tilde{A}^{2} \mathrm{~A}$ term energy (for either of the tentative assignments discussed above). Again, while the TDDFT calculations overestimate the $\tilde{\mathrm{A}}^{2} \mathrm{~A}$ term energies, the trends in relative energies are reflected consistently in our assignments, including for the two conformers that contribute to the PE spectrum of 2-propenoxide.

The PADs of features in the 2-propenoxide spectrum assigned to the $\tilde{\mathrm{X}}^{2} \mathrm{~A}-\tilde{\mathrm{X}}^{1} \mathrm{~A}$ and $\tilde{\mathrm{A}}^{2} \mathrm{~A}-\tilde{\mathrm{X}}^{1} \mathrm{~A}$ transitions are similar to those in the 1-ethoxide PE spectrum reported by Lineberger and co-workers, ${ }^{62}$ and in that the ground state transitions (for both conformers, in the case of 2-propenoxide) have more perpendicular PADs, while the close-lying excited state transitions are more parallel. The opposite is true for the 3-buten-2-oxide PE spectrum, which clearly shows a more parallel $\tilde{X}^{2} \mathrm{~A}-\tilde{\mathrm{X}}^{1} \mathrm{~A}$ transition, with the $\tilde{\mathrm{A}}^{2} \mathrm{~A}-\tilde{\mathrm{X}}^{1} \mathrm{~A}$ transition also being isotropic. The various transitions in the 3-buten-1oxide spectrum closely overlap, but the lowest energy transition, which is nearly isotropic in the spectrum obtained using $2.330 \mathrm{eV}$ photon energy, is clearly perpendicular in the spectrum obtained with $3.495 \mathrm{eV}$ photon energy (supplementary material). From a molecular structure standpoint, the most stable conformers of 2-propenoxide and 3-buten-2-oxide are very similar, differing only by the substitution of a $\mathrm{C} 1 \mathrm{H}$-atom with a methyl group, and based on the molecular orbitals from the calculations, the HOMO of the anions are very similar in appearance (supplementary material). The primary alkoxides therefore have more in common, in terms of PAD for their respective $\tilde{X}^{2} \mathrm{~A}-\tilde{\mathrm{X}}^{1} \mathrm{~A}$ transitions. The secondary alkoxide, despite the HOMO being similar in appearance, exhibits a very different $\mathrm{PAD}$, showing that (1) the methyl group affects the outbound electron wavefunction and (2) the appearance of a molecular orbital does not necessarily directly relate to PADs of electrons nominally detached from them, and vice versa.

A general outcome of the computational results is that in most instances, the higher-lying conformers are predicted to have lower ADEs. This is consistent with the presence of low $e^{-} \mathrm{BE}$ features, particularly in the 2-propenoxide spectrum. Though less prominent, there is a low intensity signal to lower $e^{-} \mathrm{BE}$ than the most intense features in the butenoxide spectra. A PE spectrum of 3-buten-2-oxide obtained under higher discharge voltage conditions is included in the supplementary material to demonstrate how the intensity of the lower $e^{-} \mathrm{BE}$ features varies with source conditions. We also note that the all experimental spectra have similar $\sim 1300 \mathrm{~cm}^{-1}$ to $\sim 1400 \mathrm{~cm}^{-1}$ progressions, which are predicted for nearly all of the conformers for all three alkenoxides presented here. While this commonality makes the simulations less informative, it simply reflects how the excess charge is localized on the $\mathrm{O}$-atom and that structural changes induce common features borne out in the experimental spectra.

\section{CONCLUSIONS}

Photoelectron imaging was used to measure the PE spectra of the 2-propenoxide, 3-buten-2-oxide, and 3-buten-1oxide radical anions, which were analyzed with supporting DFT and $a b$ initio calculations. The spectra obtained using $3.495 \mathrm{eV}$ photon energy appear qualitatively similar, with intense features in all three observed at approximately $2 \mathrm{eV}$, while the higher resolution spectra obtained using $2.330 \mathrm{eV}$ photon energy exhibited more distinctions between the three species. Partially resolved $1300-1400 \mathrm{~cm}^{-1}$ vibrational progressions are observed in all three spectra, and spectral simulations based on calculations on the anion and neutral species suggest overlapping and combination progressions in the O-bound $\mathrm{CH}_{2}$ scissor and rocking modes. Disparate PADs of various features in the spectra were used to distinguish between close-lying or overlapping $\tilde{X}^{2} \mathrm{~A}-\tilde{\mathrm{X}}^{1} \mathrm{~A}$ and $\tilde{A}^{2} A-\tilde{X}^{1} A$ transitions of at least one conformer in the $3-$ buten-2-oxide spectrum and at least two conformers in the 2-propenoxide and 3-buten-2-oxide spectrum. Based on the assignments, the $\tilde{A}^{2} \mathrm{~A}$ term energy increases from 3-buten-1oxy to 3-buten-2-oxy to 2-propenoxy. This trend is consistent with the decrease in term energy with increasing alkyl chain length in primary alkoxides but not with the decrease in term energy for secondary versus primary alkoxides. ${ }^{55}$ These results therefore show proximity to a $\pi$ bond has a significant impact on the $\tilde{A}^{2} \mathrm{~A}$ term energy, presumably due to increased interaction between the $\pi$ bond and the non-bonding $\mathrm{O} 2 p$ orbitals.

Less intense, lower $e^{-} \mathrm{BE}$ features are attributed to higher-lying conformers with lower ADEs, suggesting that the relative energies of the anion conformers are more widely spaced than for the neutral, or that higher energy conformers of the anion are lower in energy on the neutral conformer surface. Results of calculations support the former. In the case of 2-propenoxide, a higher energy conformer contributing to the spectrum has a higher $\tilde{\mathrm{A}}^{2} \mathrm{~A}$ term energy than the lowest energy conformer. Overall, the presence of close-lying conformers and electronic states may have implications for radical reactivity.

\section{SUPPLEMENTARY MATERIAL}

Supplementary material includes raw photoelectron images obtained with $2.330 \mathrm{eV}$ and $3.495 \mathrm{eV}$ photon energies of all radical anions, $3.495 \mathrm{eV}$ spectra resolved into parallel and perpendicular PADs, slices through the reconstructed images obtained using $2.330 \mathrm{eV}$ taken at $10^{\circ}$ increments, relative energies and transition states from CAM-B3LYP, comparison of hot and cold 3-buten-2-oxide PE spectra, CAM-B3LYP molecular orbitals, and the simulation parameters.

\section{ACKNOWLEDGMENTS}

The authors gratefully acknowledge the National Science Foundation, Grant No. CHE-1664965, for their generous support.

The authors declare no competing financial interest. 


\section{REFERENCES}

${ }^{1}$ M. Glasius and A. H. Goldstein, Environ. Sci. Technol. 50, 2754 (2016).

${ }^{2}$ B. J. Finlayson-Pitts and J. N. Pitts, Jr., Chemistry of the Upper and Lower Atmosphere: Theory, Experiments and Applications (Academic Press, San Diego, 2000).

${ }^{3}$ K. Sindeleraova, C. Granier, I. Bouarar, A. Guenther, S. Tilmes, T. Stavrakou, J.-F. Müller, U. Kuhn, P. Stefani, and W. Knorr, Atmos. Chem. Phys. 14, 9317 (2014).

${ }^{4}$ R. Atkinson and J. Arey, Atmos. Environ. 37, 197 (2003).

${ }^{5}$ A. Mellouki, T. J. Wallington, and J. Chen, Chem. Rev. 115, 3984 (2015).

${ }^{6}$ J. A. de Gouw, J. B. Gilman, S.-W. Kim, S. L. Avarez, S. Dusanter, M. Graus, S. M. Griffith, G. Isaacman-VanWertz, W. C. Kuster, B. L. Lefer, B. M. Lerner, B. C. McDonald, B. Rappenglück, J. M. Roberts, P. S. Stevens, J. Stutz, R. Thalman, P. R. Veres, R. Volkamer, C. Warneke, R. A. Washenfelder, and C. J. Young, J. Geophys. Res. 123, 2298, https://doi.org/10.1002/2017jd027976 (2018).

${ }^{7}$ B. Wang, H. H. Shuhart, and M. T. Lerdau, Environ. Res. Lett. 12, 084001 (2017).

${ }^{8}$ R. van Zelm, M. A. J. Huijbregts, H. A. den Hollander, H. A. van Jaarsveld, F. J. Sauter, J. Struijs, H. J. van Wijnen, and D. van de Meent, Atmos. Environ. 42, 441 (2008).

${ }^{9}$ IPCC, in Climate Change 2013: The Physical Science Basis. Contribution of Working Group I to the Fifth Assessment Report of the Intergovernmental Panel on Climate Change, edited by T. F. Stocker, D. Qin, G.-K. Plattner, M. Tignor, S. K. Allen,J. Boschung, A. Nauels, Y. Xia, V. Bex, and P. M. Midgley (Cambridge University Press, Cambridge, United Kingdom and New York, NY, USA, 2013), p. 1535.

${ }^{10}$ J. G. Calvert, A. Mellouki, J. J. Orlando, M. J. Pilling, and T. J. Wallington, The Mechanisms of Atmospheric Oxidation of the Oxygenates (Oxford University Press, New York, 2011).

${ }^{11}$ J. H. Kroll and J. H. Seinfeld, Atmos. Environ. 42, 3593 (2008).

${ }^{12}$ P. J. Ziemann and R. Atkinson, Chem. Soc. Rev. 41, 6582 (2012).

${ }^{13}$ W. P. L. Carter, K. R. Darnall, A. C. Lloyd, A. M. Winer, and J. N. Pitts, Jr., Chem. Phys. Lett. 42, 22 (1976).

${ }^{14}$ K. Y. Choo and S. W. Benson, Int. J. Chem. Kinet. 13, 833 (1981).

${ }^{15}$ W. P. L. Carter and R. Atkinson, J. Atmos. Chem. 3, 377 (1985).

${ }^{16} \mathrm{C}$. Fittschen, H. Hippler, and B. Viskolcz, Phys. Chem. Chem. Phys. 2, 1677 (2000).

${ }^{17}$ M. Blitz, M. J. Pilling, S. H. Robertson, and P. W. Seakins, Phys. Chem. Chem. Phys. 1, 73 (1999).

${ }^{18}$ H. Somnitz and R. Zellner, Phys. Chem. Chem. Phys. 2, 1907 (2000).

${ }^{19} \mathrm{~L}$. Vereecken and J. Peeters, Phys. Chem. Chem. Phys. 11, 9062 (2009).

${ }^{20}$ S. Sarkar, S. Mallick, Deepak, P. Kumar, and B. Bandyopadhyay, Phys. Chem. Chem. Phys. 19, 27848 (2017).

${ }^{21}$ R. Atkinson, Int. J. Chem. Kinet. 29, 99 (1997).

${ }^{22}$ J. J. Orlando, G. S. Tyndall, and T. J. Wallington, Chem. Rev. 103, 4657 (2003).

${ }^{23}$ R. Atkinson, Atmos. Environ. 41, 8468 (2007).

${ }^{24}$ A. Rauk, R. J. Boyd, S. L. Boyd, D. J. Henry, and L. Radom, Can. J. Chem. 81, 431 (2003).

${ }^{25}$ P. Chen, S. D. Colson, W. A. Chupka, and D. A. Berson, J. Phys. Chem. 90, 2319 (1986).

${ }^{26}$ S. C. Foster, Y.-C. Hsu, C. P. Damo, X. Liu, C.-Y. Kung, and T. A. Miller, J. Phys. Chem. 90, 6766 (1986).

${ }^{27}$ C. C. Carter, J. R. Atwell, S. Gopalakrishnan, and T. A. Miller, J. Phys. Chem. A 104, 9165 (2000).

${ }^{28}$ I. Fischer, Int. J. Mass Spectrom. 216, 131 (2002).

${ }^{29}$ T. A. Miller, Mol. Phys. 104, 2581 (2006).

${ }^{30}$ E. N. Sharp, P. Rupper, and T. A. Miller, Phys. Chem. Chem. Phys. 10, 3955 (2008).

${ }^{31}$ P. S. Thomas and T. A. Miller, Chem. Phys. Lett. 491, 123 (2010).

${ }^{32}$ N. D. Kline and T. A. Miller, Chem. Phys. Lett. 601, 149 (2014).
${ }^{33}$ D. R. Yarkony, H. F. Schafer III, and S. Rothenberg, J. Am. Chem. Soc. 96, 656 (1974).

${ }^{34}$ S. C. Foster, P. Misra, T. Y. D. Lin, C. P. Damo, C. C. Carter, and T. A. Miller, J. Phys. Chem. 92, 5914 (1988).

${ }^{35}$ M. L. Weichman, L. Cheng, J. B. Kim, J. F. Stanton, and D. M. Neumark, J. Chem. Phys. 146, 224309 (2017).

${ }^{36}$ P. C. Engelking, G. B. Ellison, and W. C. Lineberger, J. Chem. Phys. 69, 1826 (1978).

${ }^{37}$ A. Geers, J. Kappert, F. Temps, and T. J. Sears, J. Chem. Phys. 98, 4297 (1993).

${ }^{38}$ Y. F. Lee, W. T. Chou, B. A. Johnson, D. P. Tabor, E. L. Sibert, and Y. P. Lee, J. Mol. Spectrosc. 310, 57 (2015).

${ }^{39}$ Y. Endo, S. Saito, and E. Hirota, J. Chem. Phys. 81, 122 (1984).

${ }^{40}$ D. K. Russell and H. E. Radford, J. Chem. Phys. 72, 2750 (1980).

${ }^{41}$ G. D. Bent, J. Chem. Phys. 100, 8219 (1994).

${ }^{42}$ G. D. Bent, G. F. Adams, R. H. Bartram, G. D. Purvis, and R. J. Bartlett, J. Chem. Phys. 76, 4144 (1982).

${ }^{43}$ D. E. Powers, J. B. Hopkins, and R. E. Smalley, J. Phys. Chem. 85, 2711 (1981).

${ }^{44}$ I. J. J. Liu, M. W. Chen, D. Melnik, J. T. Yi, and T. A. Miller, J. Chem. Phys. 130, 074302 (2009).

${ }^{45}$ C. F. Jackels, J. Chem. Phys. 82, 311 (1985).

${ }^{46}$ S. D. Brossard, P. G. Carrick, E. L. Chappell, S. C. Hulegaard, and P. C. Engelking, J. Chem. Phys. 84, 2459 (1986).

${ }^{47}$ P. Misra, X. Zhu, C.-Y. Hsueh, and J. B. Halpern, Chem. Phys. 178, 377 (1993).

${ }^{48}$ Y.-Y. Lee, G.-H. Wann, and Y.-P. Lee, J. Chem. Phys. 99, 9465 (1993).

${ }^{49}$ J. T. Carter and D. B. Cook, J. Mol. Struct. 251, 111 (1991).

${ }^{50}$ D. G. Melnik, J. J. Liu, M. W. Chen, T. A. Miller, and R. F. Curl, J. Chem. Phys. 135, 094310 (2011).

${ }^{51}$ A. V. Marenich and J. E. Boggs, J. Chem. Phys. 122, 024308 (2005).

${ }^{52}$ S. Dertinger, A. Geers, J. Kappert, J. Wiebrecht, and F. Temps, Faraday Discuss. 102, 31 (1995).

${ }^{53}$ A. Bouallagui, A. Zanchet, O. Yakidi, N. Jaïdane, L. Bañares, M. L. Senet, and A. García-Vela, Phys. Chem. Chem. Phys. 19, 31245 (2017).

${ }^{54}$ B. A. Johnson and E. L. Sibert, J. Chem. Phys. 146, 174112 (2017).

${ }^{55} \mathrm{~J}$. Jin, I. Sioutis, G. Tarczay, S. Gopalakrishnan, A. Bezant, and T. A. Miller, J. Chem. Phys. 121, 11780 (2004).

${ }^{56}$ M. Dupuis, J. J. Wendoloski, and W. A. Lester, J. Chem. Phys. 76, 488 (1982).

${ }^{57}$ G. B. Ellison, P. C. Engelking, and W. C. Lineberger, J. Phys. Chem. 86, 4873 (1982).

${ }^{58}$ L. F. DiMauro, M. Heaven, and T. A. Miller, J. Chem, Phys. 81, 2339 (1984).

${ }^{59}$ R. D. Mead, K. R. Lykke, and W. C. Lineberger, J. Chem. Phys. 81, 4883 (1984).

${ }^{60}$ D. L. Osborn, H. Choi, D. H. Mordaunt, R. T. Bise, D. M. Neumark, and C. M. Rohlfing, J. Chem. Phys. 106, 3049 (1997).

${ }^{61}$ M. S. Bowen and R. E. Continetti, J. Phys. Chem. A 108, 7827 (2004).

${ }^{62}$ T. M. Ramond, G. E. Davico, R. L. Schwartz, and W. C. Lineberger, J. Chem. Phys. 112, 1158 (2000).

${ }^{63}$ T. I. Yacovitch, E. Garand, and D. M. Neumark, J. Chem. Phys. 130, 244309 (2009).

${ }^{64}$ P. S. Thomas, R. Chhantyal-Pun, N. D. Kline, and T. A. Miller, J. Chem. Phys. 132, 114302 (2010).

${ }^{65}$ L. S. Alconcel, H. J. Deyerl, and R. E. Continetti, J. Am. Chem. Soc. 123, 12675 (2001).

${ }^{66}$ R. F. Gunion, M. K. Gilles, M. L. Polak, and W. C. Lineberger, Int. J. Mass Spectrom. Ion Processes 117, 601 (1992).

${ }^{67}$ J. E. Mann, M. E. Troyer, and C. C. Jarrold, J. Chem. Phys. 142, 124305 (2015).

${ }^{68}$ M. A. Duncan, J. Phys. Chem. A 116, 11477 (2012).

${ }^{69}$ L. A. Posey, M. J. Deluca, and M. A. Johnson, Chem. Phys. Lett. 131, 170 (1986).

${ }^{70}$ J. M. B. A. Bakker, J. Phys. E: Sci. Instrum. 6, 785 (1973). 
71 J. M. B. A. Bakker, J. Phys. E: Sci. Instrum. 7, 364 (1974).

${ }^{72}$ A. T. J. B. Eppink and D. H. Parker, Rev. Sci. Instrum. 68, 3477 (1997).

${ }^{73}$ D. W. Chandler and P. L. Houston, J. Chem. Phys. 87, 1445 (1987).

${ }^{74}$ M. B. Doyle, C. Abeyasera, and A. G. Suits, NuAcq 0.9: Native Megapixel Ion Imaging With Centroiding to 4 Mpix Using Inexpensive USB-2 Cameras, available at http://chem.wayne.edu/suitsgroup/NuAcq.html.

${ }^{75}$ V. Dribinski, A. Ossadtchi, V. A. Mandelshtam, and H. Reisler, Rev. Sci. Instrum. 73, 2634 (2002).

${ }^{76}$ K. M. Ervin, I. Anusiewicz, P. Skurski, J. Simons, and W. C. Lineberger, J. Phys. Chem. A 107, 8521 (2003).

${ }^{77}$ G. A. Garcia, L. Nahon, and I. Powis, Rev. Sci. Instrum. 75, 4989 (2004).

78 J. Cooper and R. N. J. Zare, J. Chem. Phys. 48, 942 (1968).

${ }^{79}$ M. J. Frisch, G. W. Trucks, H. B. Schlegel, G. E. Scuseria, M. A. Robb, J. R. Cheeseman, G. Scalmani, V. Barone, B. Mennucci, G. A. Petersson, H. Nakatsuji, M. Caricato, X. Li, H. P. Hratchian, A. F. Izmaylov, J. Bloino, G. Zheng, J. L. Sonnenberg, M. Hada, M. Ehara, K. Toyota, R. Fukuda,
J. Hasegawa, M. Ishida, T. Nakajima, Y. Honda, O. Kitao, H. Nakai, T. Vreven, J. A. Montgomery, Jr., J. E. Peralta, F. Ogliaro, M. J. Bearpark, J. Heyd, E. N. Brothers, K. N. Kudin, V. N. Staroverov, R. Kobayashi, J. Normand K. Raghavachari, A. P. Rendell, J. C. Burant, S. S. Iyengar, J. Tomasi, M. Cossi, N. Rega, N. J. Millam, M. Klene, J. E. Knox, J. B. Cross, V. Bakken, C. Adamo, J. Jaramillo, R. Gomperts, R. E. Stratmann, O. Yazyev, A. J. Austin, R. Cammi, C. Pomelli, J. W. Ochterski, R. L. Martin, K. Morokuma, V. G. Zakrzewski, G. A. Voth, P. Salvador, J. J. Dannenberg, S. Dapprich, A. D. Daniels, Ö. Farkas J. B. Foresman, J. V. Ortiz, J. Cioslowski and D. J. Fox, Gaussian 09, Revision D.01, Gaussian, Inc., Wallingford, CT, USA, 2009.

${ }^{80}$ T. Yanai, D. P. Tew, and N. H. Handy, Chem. Phys. Lett. 393, 51 (2004).

${ }^{81}$ R. A. Kendall, T. H. Dunning, and R. J. Harrison, J. Chem. Phys. 96, 6796 (1992).

${ }^{82}$ A. I. Krylov, Annu. Rev. Phys. Chem. 59, 433 (2008).

${ }^{83}$ R. N. Schaugaard, J. E. Topolski, M. Ray, K. Raghavachari, and C. C. Jarrold, J. Chem. Phys. 148, 054308 (2018). 